\title{
Through the eye of a needle: the emergence of a practice-led research doctorate in music
}

\section{Paul Draper and Scott Harrison}

Queensland Conservatorium Griffith University, 140 Grey Street, P0 Box 3428, South Brisbane, Queensland, Australia

p.draper@griffith.edu.au, scott.harrison@griffith.edu.au

This paper explores recent developments in relation to doctoral research training in music. Drawing on the findings of a case-study of a recently established practice-led doctorate at an Australian conservatoire, we offer insights into the attributes of its expanding cohort. We interrogate a blended research training structure of academic supervision, coursework, web-based tools and administrative resources in order to reveal the obstacles to, and opportunities for improvement. The paper concludes by arguing programme design refinements which contribute to a deeper understanding of practice-led doctorates in music while inviting readers to similarly consider their own experiences.

\section{Introduction}

Eyes of needles are notoriously difficult to thread, leading to the aphorism based on the difficulty of forcing a large animal through a small opening. The analogy with the creative and performing arts and Western universities provides a useful viewpoint from which to consider the assimilation of formerly independent education providers within the academy. These include teacher training organisations, art colleges, and as especially central to this discussion, conservatoria. In Europe, the Bologna Declaration Process continues to drive investigations in these domains and is monitored in Australia given similar interests and benchmarking aspirations. While initial attention has focused upon first- and secondcycle undergraduate and masters education, emerging 'third-cycle' doctorates in music are of particular interest to this study given an increasing demand at the authors' institution, together with a shift of emphasis for what was formerly a vocational discipline. The Polifonia Third Cycle Working Group writes:

... conservatoires traditionally offer vocational training that leads to a career as a professional musician, composer, or in some cases also as a music teacher ... Offering Third Cycle or doctoral studies has historically been the preserve of universities ... It would seem logical to be able to research and communicate about music in all circumstances and from all aspects within the institution that deals most specifically with it and by those people who are executants, rather than confining this activity to those institutions that happen to offer musicology as a scientific study field. For this reason amongst others, professional music training institutions have started to offer doctoral studies of different kinds as well. (Polifonia, 2007, p. 9)

Correspondence to Paul Draper 
Related, Tuning Education Structures was set up as an evaluation framework for the Bologna Declaration Process. According to Tuning (2004), doctoral programmes in Europe are still the weakest part of many universities, and discussions have concentrated on generalities even though there are significant differences between disciplinary domains. Similarly in Australia, conflicting approaches are apparent for arts-based doctorates:

... many universities give very little guidance and others are very specific about the requirements. As a result the expectations of what a practice-based doctorate should be vary widely, and this poses a number of problems relating to awareness of doctoral award requirements across the sector, and acknowledgement and understandings of academic and artistic standards. (Hannan, 2008, p. 1)

\section{Locating artistic research}

In the past, music PhDs have utilised well-trodden approaches with outcomes including musicology dissertations and composition portfolios. More recently, driven by governmental research assessment, there have emerged a range of equivalency arguments for artistic practice by universities and academics eager to establish research bona fides in relation to attracting grant income, tenure track and promotion, and as also essential to the culture - doctoral completions. In Britain, the Arts and Humanities Research Council (AHRC) adopted the term practice-led research and many institutions have followed suit elsewhere. On the one hand, this evokes essential relationships between theory and practice, while on the other hand, it suggests methodologies that differentiate artistic research from the mainstream. Similarly, the Australian Higher Education Council urged universities to 'provide extended and advanced training in professional fields where projects were applied in nature and oriented to practice' (AHEC, 1989, p. 7). Subsequently, the 'professional doctorate' has become significant in Australia as a qualification for practice-led disciplines including education, nursing, law and music. However, as Huib Schippers cautions:

Although much music making involves research, the latter does not necessarily qualify all music making as research. Not every rehearsal is a research project, and not all performances are research outcomes. If we follow the OECD definition that research and experimental development comprises 'creative work undertaken on a systematic basis in order to increase the stock of knowledge, including the knowledge of man, culture and society, and the use of this stock of knowledge to devise new applications' ... then much of what musicians do may certainly be high-level professional practice, but all does not necessarily constitute research. (Schippers, 2007, p. 2)

Conversely, there is also resistance from some academics who view that the inclusion of artistic practice within a research paradigm can only harm a discipline oriented to craft and tacit know-how; that this will reduce music making to 'what is demonstrable, while apparently successfully ticking the boxes of orthodox protocols with regard to research questions, literature review, data gathering and analysis' (Coessens et al., 2009, p. 22). Nonetheless, irrespective of any misgivings about forcing the arts through the eye of an academic needle, the authors wish to engage with what may be evolving as coherent approaches to practice-led research in music. Our starting point is to build upon traditional 


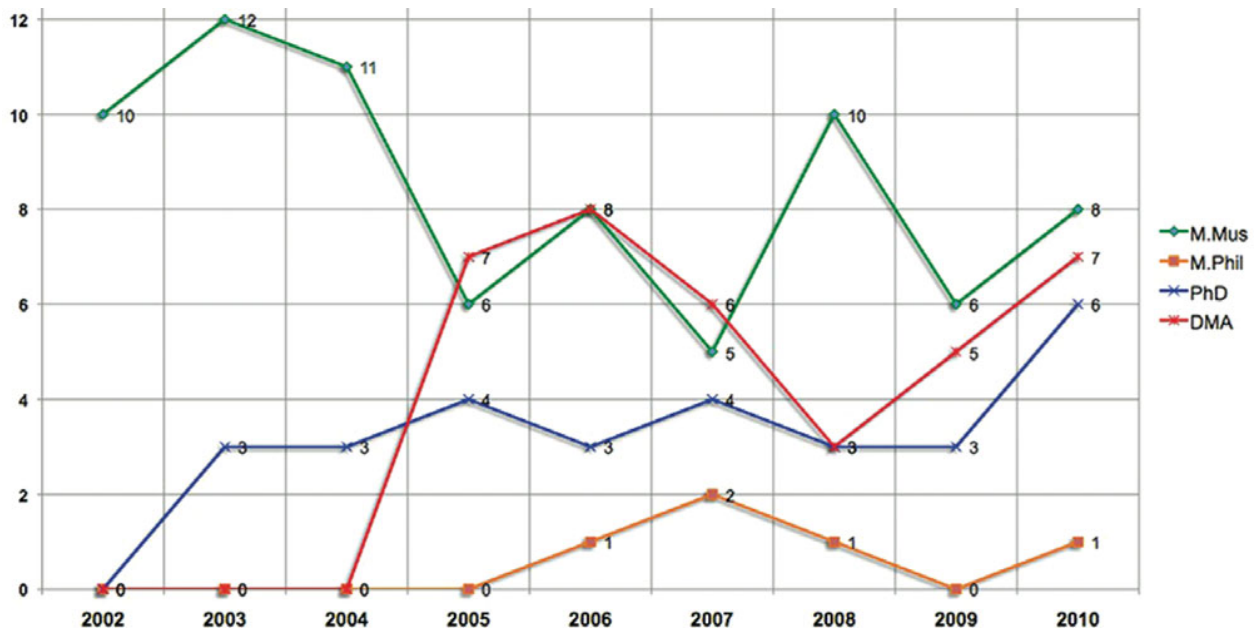

Fig. 1 QCGU Research Higher Degrees new students commencing, 2002-2010

research methodologies, or to cite a recent proposition, 'from hunter-gatherer culture [borrowing from other disciplines] to agricultural culture [growing your own]' (Dejans \& Vanmaele, 2009).

\section{Locating the study}

In this study we examine the Doctor of Musical Arts (DMA), a professional doctorate by research programme established in 2005 and located at the Queensland Conservatorium Griffith University (QCGU) in Brisbane, Australia. Entry to the DMA requires candidates to possess a minimum of five years professional experience, preferably with a formal research training qualification, but commonly accepting high level professional experience in lieu. Consequently, the programme's design provides part of its structure as coursework and the remainder as exegesis, while simultaneously meeting the Australian government threshold to be funded as an RHD. The DMA commenced with a burst of enrolments in 2005 and 2006, followed by a correction in 2008 where some candidates withdrew given matters of workload, prior skills and/or suitability for research undertakings. Since 2008 however, the DMA profile has continued to refine and expand, while overall RHD growth mirrors this trend, as shown in Figure 1.

As numbers continue to increase this brings additional pressures on faculty resources, especially in relation to staff to student ratios. In stark comparison to QCGU's modest 2004 research training load, in 2010 there are now in excess of 70 RHD candidates, as shown in Figure 2.

In 2009, QCGU graduated its first DMA and this touchstone provides a point at which to take stock of the programme. We are interested in the accelerating RHD enrolments, apparently triggered by the DMA's introduction. In particular, what kinds of backgrounds and aims DMA candidates bring, how they view their practice-led investigations and how 
2004 RHDs continuing (28)

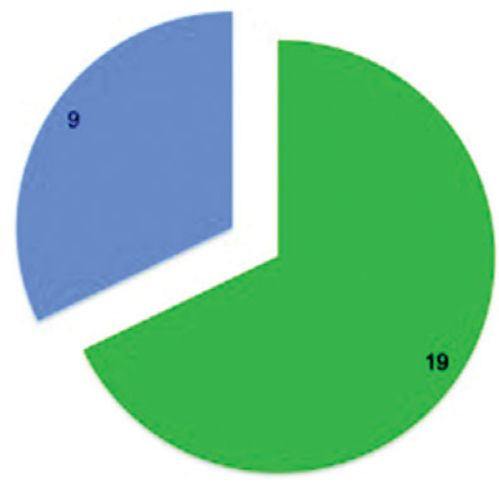

2010 RHDs continuing (71)

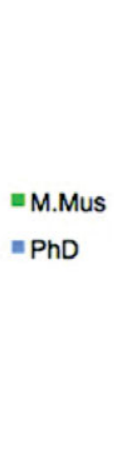

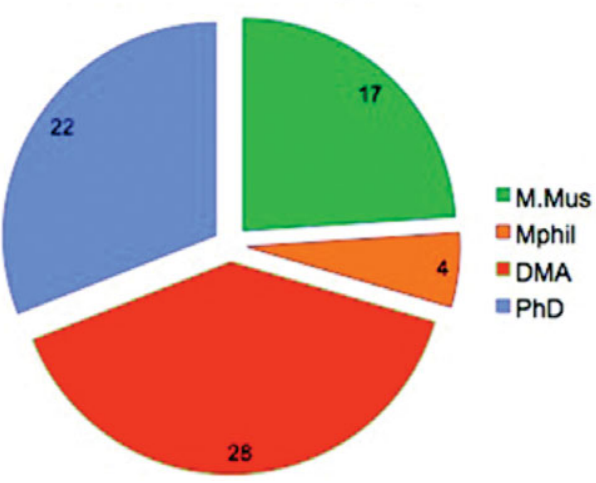

Fig. 2 QCGU Research Higher Degrees continuing, 2004 and 2010

we interface with this through the programme's coursework, academic supervision and administrative practices.

\section{Methodology}

Our research methodology draws on our experiences as academic supervisors and managers of QCGU's RHD programmes. Mixed method approaches (Creswell, 2003) were employed to review materials over a 2-year period from 2008 to 2009. Data were gathered from candidate surveys, interviews and faculty colloquia, and analysis was undertaken via a constant comparative method (Glaser, 1993). Notes and email correspondence were used to refine our thinking, as were meetings to discuss RHD projects, supervisory issues or sometimes unexpected university policy versus practice implications. Pragmatically, this process assisted our understanding of problem-solving through reflection in action (Schön, 1987), while developing insights were published along the way (Harrison \& Emmerson, 2009). Emergent themes were tested through cohort member checking (Lincoln \& Guba, 1985) and in refining our terms of reference, we borrowed on practice-led thinking in the visual arts to maintain a focus on the formal structures and activities involved:

By 'practice-led' I mean, firstly, research which is initiated in practice, where questions, problems, challenges are identified and formed by the needs of practice and practitioners; and secondly, that the research strategy is carried out through practice, using predominantly methodologies and specific methods familiar to us as practitioners in the visual arts. I am assuming 'strategy' to encompass all the activities involved in the planning and conducting of formal research for higher degrees issues of research infrastructure, resourcing, supervision, research student training, methodologies, examination, dissemination, etc. (Gray, 1998, p. 3)

In preparation for this article, we circulated draft extracts to DMA candidates $(n=21)$ in a discussion paper. Ten questions were designed to focus the cohort on a debate about research rationale, the programme structure, and the idea of practice-led research 
(see Appendix 1). While earlier research cast the data collection net quite wide, here we wanted to probe a little deeper by focusing on five indicative candidates across a range of progression stages and perspectives. These include record production (D1), jazz composition (D2), instrumental music performance (D3), singing and education (D4), and electroacoustic design (D5). Here, we present a summary of our co-constructed dialogue between these doctoral candidates and our discussion paper, informed by other data sources as described above.

\section{Why do a doctorate in music?}

D1 is a record producer who teaches in an Australian Technical and Further Education (TAFE) college. He is a distance student, located some $1700 \mathrm{~km}$ from QCGU. He understands his professional practice well, but aspires to 'academic 'cred' in [his] own eyes'. In his teaching role, he 'didn't want to feel like I was winging it in that fundamental area of my work'. D1 has now completed first-year coursework of the DMA, leading to confirmation. He believes that he is beginning to understand the nature of practice-led research and how this applies to him:

I am seeing great benefits to my art because of my research. It is adding clarity and the rigour of research sits very comfortably with the art of record production. It is paying the respect to the art that I feel it deserves, without distorting it.

D2 is a tenured music lecturer in her second year of DMA study. Her original view of research was construed as 'writing a paper or a book ... or analysing the [musical] arrangements of $X$, or surveying how and why students practice'. She had not considered whether playing the piano and writing music constituted formal research, 'It was just what I did ... acquiring the skills of the trade, internalizing musical vocabulary, applying knowledge to performance situations, or simply expressing myself'. However, during the course of the DMA, D2 began to affirm that,

... the notion that my own practice could be the subject of research, or could itself BE research was entirely new, and it was this that actually inspired me to undertake the DMA.

D3 is QCGU's first DMA completion and another distance candidate. D3 describes herself as a flautist, teacher, performer, concert producer and researcher. Her original aim was to incorporate real-time performance and research milestones across her candidature. However, given university policy, this had to be adapted to present a self-contained submission for final examination. Consequently, her views about the nature of her research and the DMA have changed over time:

In the beginning: a search for new experience and connections that vivify and extend thinking and practice - a new pathway that focuses on strongest individual professional interests. In the middle: questionable outcomes, but still motivated by idealistic outcomes as work through labyrinthine processes. At the end: personal questioning; bashing on doors; need to extend research ... 
D4 is a singer and teacher who has undertaken all of his first- and second-cycle studies at QCGU and is now in the latter half of his doctorate. He acknowledges the potential of the DMA to assist in academic employment and to 'secure a position of standing within my professional community', but cites his primary motivation as 'a personal drive to better myself first and develop those around me, second' and that qualifications are not an end in themselves:

Artists are 'perfectionist' by nature. The need to attain the highest standard is not foreign to our kind, and so it is only natural that the quest for a doctorate - the highest academic degree - would capture the imagination and subsequent pursuit by the artist.

D5 is a composer and sound designer who came to academic life 'by accident' some five years ago as the head of a music technology department at a private college. He had no prior research training until he completed a Master of Music at QCGU, then articulating to the DMA. Overall, he has found the meshing of cultures and commitments a challenge:

[I was] largely unaware of 'conventions' or politics of research prior to beginning DMA ... unable to pursue research to the timeframe I want due to work and family commitments ... struggled financially, necessitating switch to part time study and full time work.

Nonetheless, D5 will soon submit what he aims to be an interactive and innovative exegesis. Overall he recognises the need to attain the qualification in order to progress his employment options, but also offers that he has 'a very strong personal drive to understand my subject, and the doctorate gives me both the excuse and the opportunity to do so, with the support of some amazing minds.' He has a desire to disseminate his research, but also noted that he does not expect the doctorate to have any value outside the academy.

\section{About RHD growth}

Certainly one reason for growing numbers of RHDs is that such qualifications are increasingly required by music education institutions and in some professional circles. However, while the prospect of 'gainful employment' is one strong driver, this does not appear to be the primary consideration for most. Candidates empathise with the aspirational Dublin Descriptors for Third Cycle Awards in Music (Polifonia, 2007, p. 20), and clearly, their imagination and commitment has been engaged by ideas of personal growth, intellectual pursuit and knowledge transfer. Additionally, the relaxation of formal academic entry requirements allows for increased numbers of professional musicians to undertake a doctorate, despite the fact that most are managing busy careers or that scholarships are not usually awarded for professional doctorates. It was less clear as to why they chose QCGU. It would appear that QCGU's research centre has had some part to play in this given staff profiles, grant successes, publications and performance outreach. However, what is notable is the exponential growth of all RHD enrolments at QCGU (see Figures 1 and 2, above), and some data cite the activities of the DMA cohort itself as an essential element in driving this - made highly visible by coursework outcomes, online materials and explicit practice-led research discussion in trans-programme RHD colloquia. 


\section{The DMA programme design}

The DMA was initially based on a PhD format, but with significant support additions given that Australian government policy allows for up to one third of a research programme to be delivered as coursework. DMA courses aim to foster generic skills which normally might have been carried out in earlier research training pathways, including writing research proposals, undertaking literature reviews, developing a methodology, etc. Academic supervisors are assigned, and a dissertation must be externally examined at end of candidature. As stated earlier, there was also a desire to 'grow our own' authentic methodological arguments and exegetical models for practice-led research. As part of this aim, technology coursework is offered in the second year of the programme, while faculty-wide peer review is intended to be engaged through RHD colloquia and an online blended learning framework. Each of these programme elements are now interrogated according to candidate perceptions and reactions to the authors' probes.

\section{Coursework}

First year coursework takes the form of two, sequential offerings to advance the understanding of research method and design. The courses are team taught, each academic presenting various approaches to scaffold the development of a research plan. The courses conclude with the assessment of a short paper presenting candidates' interpretations of the topics and to be utilised as building blocks for the more substantial confirmation document shortly thereafter. Most candidates are positive about this approach, finding 'the linear structure of the DMA ... sound and helpful (D3), and that 'the practical application of method and design so early relieves what I have seen to be a substantial anxiety in other people's doctoral experience' (D1). Moreover, even those with former academic qualifications commented on the unsuitability of these for providing foundation research skills, for example:

I have a Masters degree ... but [with] no background in formal, high level research ... my research consisted of writing and playing music over the years rather than being involved in the world of academic writing about music ... I was fully ignorant of the entire context and current philosophy in qualitative research - ethnography, auto-ethnography, narrative enquiry - I wasn't even sure what 'methodology' meant, let alone 'ontology' or 'epistemology'. (D2)

My lack of research training is a direct result of a lack of emphasis on research and its potential benefits during my undergraduate years ... It was all about playing, and we were told that our four year BMus degree was equivalent to an Honours degree. This turned out not to be the case. (D4)

The most common arguments for improvement were in terms of providing specific and extended training in academic writing:

I would have liked more detailed, perhaps elective, training in specific research methods, e.g. auto-ethnographic writing, or qualitative analysis etc. via specialist research trainers. (D5) 
Other suggestions become highly personalised or problematic. For example, in technology courses, enthusiastic but often naive expectations for DIY proficiencies included that of web-site building, video production, sound recording, or interactive design - perhaps better representative of a disciplinary specialisation than a short elective. Technology in all its burgeoning forms appears to have been approached as a panacea for the representation of practice-led research and clearly, there needs to be better articulated a rationalisation and 'fitness for purpose' for exegetical design. Some expected that these matters should fall to supervisor responsibility, but relevant expertise (or time) cannot reasonably accommodate this. More broadly, effective modes of coursework delivery are a work in progress. In the programme's first iteration, courses were offered as face-to-face weekly classes, but this proved to be a challenge given the professional commitments of some candidates, alongside an increase in numbers of distance enrolments. In 2008, coursework was re-framed as 'intensive' delivery, that is, to provide suitable weekends for all candidates to attend on campus. This was conceptually supported by an e-learning platform ('Learning@Griffith') to coordinate the further development of the candidates' assessment items. In practice however, we find that online resources have been poorly utilised to date, and that the primary burden is deflected to thesis supervisors, usually via email traffic.

\section{Research supervision}

QCGU supervisors fall broadly into two camps: those with PhDs and orthodox assumptions about research; and those with extensive musical expertise but who do not 'typically produce exegetical writings as adjuncts to their own professional outputs' (Hannan, 2008, p. 4). At first glance this presents conundrums, however, we observe that a distinctive research culture is beginning to emerge precisely because of this interaction 'between cosupervisors of different disciplines and between the theoretical and the practical aspects of the project' (Evans \& Gandolfo, 2009, p. 12). It is this very access to differing viewpoints that is viewed most positively:

Supervisory relationships have developed into valued professional and personal relationships despite occasional differences of opinion, perspective and expression. In an environment where DMA students have significant professional background, this seems a healthy thing, and the relationships should be able to progress from a basis of mutual respect. (D5)

It is not entirely different to being in a band. The different perspectives are creating clarity rather than confusion, and if there are any straight contradictions, this encourages me to really focus my own opinion. I have found the contributions very clear and helpful, and I feel I have enjoyed a very well supported autonomy ... the supervisor/DMA student relationship has similarities within the popular musical culture, like a band or an artist with a producer. (D1)

More critically, a common complaint was in what was perceived as untimely responses and/or regular access to supervisors. For example, 'I have had some difficulty accessing [my] principal supervisor due to timetabling and other duties' (D3), and that 'immense frustration occurred when the structure for responses failed ... this includes email [and] phone call arrangements, and personal visits' (D4). Underpinning this are important mixed 
assumptions about responsibilities, just what kind of direction is to be provided, and by whom:

... that 45 minutes per week was allocated for supervision meetings/email responses/phone calls. The actuality was very different from this. It is understood that not everyone can respond immediately to work, or be available all the time for consultation, but the arrangements/rights/expectations need to be much clearer to avoid very significant difficulties. (D4)

DMA students need a clearer understanding of how their work 'fits in' and is a part of funding, university politics and government views of research value. These are things that we pick up by osmosis, including the vast number of abbreviations and acronyms.

(D5)

Some confusion comes from not understanding the component parts of the programme and/or the faculty itself in not better signifying boundary responsibilities. Unless the academic is one of the few who teach in DMA courses, perceptions may be unclear about the role of coursework in a given research project. Elsewhere, participants are not necessarily cognisant of the programme's general processes, including the fact that all RHD administration - from application, to scholarships, confirmation, ethics, submission, examination and correction - is governed by university policy within a centralised Graduate Research School, not by the faculty. Without such awareness, each and every enquiry from candidates may be channelled to supervisors. Therefore what is unique to the programme must be clarified and better disseminated: that the DMA offers dedicated coursework and teachers for certain developmental aspects; it provides centralised and thoroughly documented resources for programme administration; it assigns expert supervisors to assist in the development of research projects; it supports the engagement of RHD peer review; and it provides web-based resources as a structural 'glue' across these elements.

\section{Flexible resources}

Despite the widespread adoption of blended learning approaches in undergraduate education (Bersin, 2004), it would appear that there have been few attempts by research training units to fully engage with online technologies. Given common characteristics of the DMA cohort - that is, professional commitments, time management issues, distance candidature and so on - 'blended research training' is an area that QCGU would like to progress. However, early attempts have been somewhat piecemeal and met with varying levels of resistance, for example:

I spend so much time in front of the computer doing admin for my job that the last thing I want to do at home is log on to access materials for my studies. (D2)

Some candidates become constrained by lack of direction, too many choices, and/or information overload. To date, the most widely acknowledged RHD 'flexible resource' has been email (Harrison \& Emmerson, 2009), yet often revealed as a form of undisciplined dependency where the timing may well suit the candidate, but the same information overload is passed on to the academic supervisor. While managed email interchange can no doubt be part of an overall solution, we also need to build greater efficiencies through 
the strategic use of other asynchronous and/or collaborative tools 'fit for purpose'. Here, an umbrella website might be enculturated across the RHD cohort, as D5 suggests:

... it seems to me that part of the success of the undergrad uptake of these resources is the requirement to do so (along with a general Gen $\mathrm{Y}$ acceptance of the technologies).

(D5)

A faculty-wide RHD colloquium has been a well-received step toward this, and where possible, a website mirrors these events through lecture notes, videos and other archives. With presentations by specialists, supervisors and the research candidates themselves, RHD colloquium notably shares the evolving practice-led culture through peer interactions.

Overall, candidates need to be alerted to their responsibilities to be committed to their federally funded and highly competitive RHD places, and part of this is in committing regular study time to coursework. If lecture notes, reading materials and assessment tasks are located online, then clearly these need to be utilised. In terms of faculty responsibilities, the idea of web-assisted learning needs to be met with greater pedagogical forethought than it has to date, and the well-designed use of e-resources has the potential to lead by example the development of candidates' methodological aspirations. This includes via the provision of research exemplars, peer interactions, audio-visual colloquia archives, and in commonly used web 2.0 tools including discussion boards, wikis and weblogs.

The exegesis

The rush to technology might be expected given the DMA guidelines. The final exegesis may be presented as a written thesis (60-80 000 words), or as a portfolio of creative materials accompanied by a written document that contextualises the work and its contribution to the field (minimum 20000 words). Some of the research materials may be submitted in digital formats including CD, DVD or website. While this approach opened the doors for experimentation, it became obvious that QCGU was 'feeling its way forward in the DMA' (D5). Some candidates felt that they needed more formal early guidelines, and that 'it should be possible to improve the student's perception of all of this. My experience was muddled - and, in fact, never made clear until I was virtually at submission' (D4).

There have been lessons learned here, especially where some propositions have collided with university policy. For example, the so-called 'website' option proved problematic given certain assumptions by the less technologically astute. In the case of D5, his project focuses on modelling artistic decision-making in a non-linear format seemingly well-suited to a web-based submission. However, it is also clear that a 'live' website cannot be guaranteed as final, replicable or as necessarily accessible to external examiners. Subsequently, a simple modification to the guidelines was made in that this kind of submission should be presented as a 'canned' website, that is, as self-contained, navigable html and multimedia resources on read-only media.

In other cases, there was the expectation that live performance would play a greater part in progressively staged examination processes. However, it is not the case that QCGU delivers a US-styled performance doctorate, to some degree governed by Australian RHD funding rules, but also because of the aforementioned quest by QCGU to better articulate the differences between professional practice and practice-led research. A softer barrier 
is that university policy requires doctoral theses to be examined as a self-contained final submission. Nonetheless, in ongoing discussions it would appear promising that adjustments might be argued given the time-based, interactive nature of music as a discipline. Before we proceed further though, the culture needs to become more certain about its arguments for research components and weightings.

\section{Confirmation}

It would appear that the preceding analysis uncovers deficiencies in the confirmation process. Here, candidates not only make a proposal for the structure of the written document, it is also intended that they argue the overall format according to the DMA guidelines mentioned above. The document could have a word-count of anywhere from 20000 to 80000 words, with the non-trivial gap in this range met by research portfolio components. With the assistance of supervisors, a rigorous case is intended to be made about the weightings of these elements. In practice however, confirmation tends to mirror a traditional approach where the written document, its research questions, literature review, and method attract the most scrutiny, and much less so against potentially innovative portfolio possibilities. Candidates write:

At the time of confirmation, the mode of presentation was such a vague concept it was simply not dealt with adequately. I am still unsure of 'how much is enough', although I don't think 70K words is going to be a problem! The 'value' of the [creative] works however is very unclear. (D5)

I felt in retrospect that much of this was ill-informed. Having been advised to include, for example, suggested weightings for submission elements, this turned out to be fictional (with regard to performance and materials) as in the end my assessment was entirely thesis based. (D4)

In any research project it is difficult to predict a final outcome some two to three years out from completion - practice-led or otherwise. However, it is likely that more can be accomplished in terms of prompting candidates, supervisors and examiners as to just how portfolio-based research designs might be presented, and of a range within which the confirmation might judged. This could include music-making elements or multimedia drafts as components and/or assessment stages to better propose exegesis options within confirmation.

\section{Conclusions}

In reflecting upon these growth pangs, it is worth reviewing the nature of research and artistic practice once again. Until recently, doctorates in music were largely conducted within the domains of either (i) musicology-styled dissertations similar to that of science PhDs; or (ii) via composition portfolio accompanied by analysis similar to that of a PhD by Publication format. This second example is distinctly different to the first however, in that it exemplifies what colleagues in art and design term 'material thinking' (Adamson, 2007). That is, artists produce 'products' - tangible, physical artworks which are part of an answer to research questions when designed appropriately, 'to articulate the character, techniques 
and outcomes of creative research in a way that preserves the material difference of its discourse' (Carter, 2005, p. 7). Carole Gray and Gordon Burnett add:

... this is not a hermetic practice, an exclusive dialogue between artist and materials. Rather 'good techne' is the craft of shaping or combination - open to criticism and correction. The outcomes of these collaborations demonstrate 'local knowledge' ... one of the 'distinctive yields' of creative research. (Gray \& Burnett, 2009, p. 45)

Producing creative products for scrutiny as doctoral work is also common in film-making and sits comfortably within popular music areas where sound production aspires to professionally acknowledged standards for artistic design. In the case of instrumental performance or voice specialisations however, just like candidates' self-proclaimed lack of writing skills, a surprising lack of confidence is evident in terms of 'just what do performers make'? What are our research 'products'? And, this is where the terms of the DMA guidelines have become 'muddled' for some (D4) - just as 'not every rehearsal is a research project, and not all performances are research outcomes' (Schippers, 2007, p. 2), neither is every amateur recording or website an equivalent research output weighted in lieu of word-count, prima facie. For those who wish to focus their doctoral studies accordingly, this may be one of the most pressing areas for methodological cultivation: that material thinking in response to research questions may be exemplified through music making activities, and if so, how then this is to be most effectively progressed as portfolio for authentic multi-component exegeses.

The emergence of practice-led research methodologies

Here, Liora Bresler's thoughts resonate with many of our experiences thus far, that meaningful approaches and outcomes are emerging through

... the seeming oxymoron of hard work and sophisticated skills, and the playful spontaneous, responsive frame of mind that accommodates disciplined improvisation ... an interplay between script and exploration, tradition and innovation. Obviously, improvisation is harder for students who typically lack research experience and possess less developed research skills. Still, the habit of mind of improvisation and its contributions as enhancing methodological options can be attended to and cultivated or ignored and quenched. (Bresler, 2009, p. 18)

Our starting point has sought to utilise established approaches in order to cultivate a unique agricultural research culture, some of which has been signalled by the portfolio aspirations, where 'every single artistic researcher is inevitably faced with the task of figuring out how, in her/his specific research, artistic and linguistic modes of expression can be inserted, combined and connected' (Cobussen, 2010, p. 54). Positively, this same multi-modal quandary is driving multi-method research design as increasingly common practice for DMAs (albeit, largely text-based for the moment). Distinctly compelling in comparison to some musicology tomes of old, candidates' qualitative, reflective and ethnographic writings now begin to provide a chart through unfamiliar territory, inviting new improvisations on the idea of practice-led research. For example, D4's original time-based performance proposal was later re-vamped into a substantial multi-voice dissertation accompanied by 
media appendices and well-received by international examiners. Subsequently, D2 and her supervisors picked up on this in her study of her development as a jazz musician. Her recent confirmation convincingly proposed an auto-ethnographic approach (Bartleet \& Ellis, 2009) as an overarching framework to incorporate a unique triangulation that includes recordings of her original compositions as one of the constituent narrative components.

\section{Implications}

This study has taken stock of the progression of the DMA programme since its establishment. To do so, we have examined a series of themes including aspects of candidates' profiles, programme design elements, and the salient features of QCGU's emerging practice-led research thinking. In each case we explored the tensions, reflections and suggestions for refinement as component parts of the overall process. Here we now summarise our findings via a number of goals for the next stage of the programme's evolution:

- That supervisors and candidates understand the unique structure of the DMA. This includes dedicated coursework and teachers; centralised administrative support; specialised research design advice; an engaged RHD peer group; and blended research training resources.

- That in clarifying the above, undue supervisor workload issues will be alleviated, while simultaneously, candidates become clearer about managing both their supervisor and their candidature though the use of fit-for-purpose resources.

- That this will be accomplished by re-focusing and providing explicit orientation in RHD colloquia, coursework, and regular supervisor fora. These processes will also highlight notable aspects of the emerging agricultural research culture.

- That blended research training engage with online technologies in support of distance candidates, exemplars, peer review, and other generic research skills (including academic writing) while modelling the use of technologies for research portfolio.

- That RHD colloquia be leveraged on-line across the entire candidate and supervisor cohort.

- That a component of faculty strategic funds to be allocated to DMA scholarships, requiring a service component which assists in the development of practice-led research exemplars.

- That doctoral confirmation be better devised to cultivate multi-modal research presentations, while other public review and dissemination milestones be introduced across the candidature, including that of a final defence seminar prior to external examination.

Alongside these aims there is an ongoing necessity to monitor the process from constituent perspectives including those of the lead academic clusters of performance, technology, composition and education within QCGU's research centre, as well as across external practice-led research training fields more broadly. As outcomes become ever more lucid, it will therefore be the centre's responsibility to inform university doctoral policy, and where necessary, to advocate the broadening of boundaries for currently accepted music research paradigms. 


\section{Closing remarks}

Most would be aware that the 'eye of a needle' comes from a famous phrase found in the synoptic gospels, that 'it is easier for a camel to pass through the eye of a needle than for a rich man to enter the kingdom of God'. The camel also appears in a lesser wellknown Arabic parable, 'the camel's nose'. In this, the camel begs and eventually receives permission to insert her nose into a desert tent. However, this is soon followed by other parts of the body until the camel is completely inside, its large frame now occupying the entire space and refusing to leave.

In closing, we can't help but offer that this wonderful picture presents a promising analogy, that creative and performing artists will increasingly colonize, then dominate their own unique research space. As we have seen at QCGU, the musical nose is now well inside the academic tent and influencing all around it. Further, the pressing contemporary urgency of the greying academic population opens the way for next generations of doctorates to enter the academy, to progress and redefine musical practice across all the cycles of music education, less informed by orthodox academic assumptions but more so by authentic practice-led knowledge work. Or as our first DMA graduate puts it, 'out of the doing, the action, the temporal realisation of the music - the only place knowledge of performance can really be found'.

\section{References}

ADAMSON, G. (2007). Thinking through Craft. New York: Berg.

AHEC (Australian Higher Education Council) (1989) Australian Graduate Studies and Higher Degrees. Report by the National Board of Employment, Education and Training. Canberra: AGPS.

BARTLEET, B-L. \& ELLLIS, C. (Eds) (2009). Music Autoethnographies: Making Autoethnography Sing/Making Music Personal. Brisbane: Australian Academic Press.

BERSIN, J. (2004) The Blended Learning Handbook: Best Practices, Proven Methodologies, and Lessons Learned. San Francisco: Pfeiffer Wiley.

BRESLER, L. (2009) Research education shaped by musical sensibilities. British Journal of Music Education, 26, 7-25.

CARTER, P. (2005) Material Thinking: The Theory and Practice of Creative Research. Melbourne: Melbourne University Press.

COBUSSEN, M. (2010) The intruder. In C. Caduff, F. Siegenthaler \& T. Wächli (Eds), Art and Artistic Research: Music, Visual Art, Design, Literature, Dance (Bilingual edition, pp. 46-55). Chicago: Chicago University Press.

COESSENS, K., CRISPIN, D. \& DOUGLAS, A. (2009) The Artistic Turn: A Manifesto. Collected writings of the Orpheus Institute. Ghent: Leuven University Press.

CRESWELL, J. W. (2003) Research Design: Qualitative, Quantitative, and Mixed Method Approaches. London: Sage.

DEJANS, P. \& VANMAELE, J. (2009) Learning and Teaching in Research Higher Degrees: Local and International Perspectives. Orpheus Institute presentation to Queensland Conservatorium RHD colloquium, 21 October 2009, Brisbane, Australia.

EVANS, M. \& GANDOLFO, E. (2009) Collaborating with the enemy. TEXT, 6 [Special Issue Website Series]. GLASER, B. (1993) Basics of Grounded Theory Analysis. Mill Valley: Sociology Press.

GRAY, C. (1998) Inquiry through practice: developing appropriate research strategies. In P. Strandman (Ed.), No Guru, No Method? Discussions on Art and Design Research (pp. 82-95). Helsinki: University of Art \& Design. 
GRAY, C. \& BURNETT, G. (2009) Making sense: An exploration of ways of knowing generated through practice and reflection in craft. In Proceedings of The Crafticulation \& Education Conference, 24-26 September 2008. Helsinki: NordFo.

HANNAN, M. (2008) Unruly rules: Guidelines for Australian practice-based doctorates in music. In Proceedings of The 28th International Society for Music Education (ISME) World Conference, 2025 July, Bologna, Italy.

HARRISON, S. \& EMMERSON, S. (2009) The challenges of supervision of a doctorate in practicebased research in music: perceptions of students and supervisors. TEXT, 6 [Special Issue Website Series].

LINCOLN, Y. S. \& GUBA, E. G. (1985) Naturalistic Inquiry. Newbury Park: Sage.

POLIFONIA (2007) Guide to third cycle studies in higher music education. The 3rd cycle working group, Association Européenne des Conservatoires, Académies de Musique et Musikhochschulen (AEC), The Netherlands. Retrieved 12 August 2009, from http://www.bologna-and-music.org/home.asp?id= 1766

SCHIPPERS, H. (2007) The marriage of art and academia: challenges and opportunities for music research in practice-based environments. Dutch Journal of Music Theory, 12, 34-40.

SCHÖN, D. A. (1987) Educating the Reflective Practitioner: Toward a New Design for Teaching and Learning in the Professions. San Francisco: Jossey-Bass.

TUNING (2004) Tuning Education Structures in Europe. An Educational Evaluation Framework for the Lisbon Strategy and the Bologna Declaration Process. [Website]. http://tuning.unideusto.org/tuningeu (accessed 27 October 2009).

\section{Appendix 1:}

Discussion paper - On being and becoming a Doctor of Musical Arts.

A discussion paper was circulated to DMA candidates, aiming to test the authors' interpretations of earlier data analysis and to better understand and integrate the respondents' perceptions of these matters. The paper was arranged under ten broad topics, each concluding with the following questions: 
1. About you

2. Why a doctorate?

3. Locating artistic research - in your lived experience

4. Practice-oriented research terminology

5. Practice-led research - in your project

6. Programme design

7. Research supervision

8. Flexible resources

9. The exegesis

10. Generic capacities
Describe yourself, your professional setting and approach to your doctoral studies.

Bands, concert halls or film sound stages do not usually demand formal qualifications, only expertise. Why would a musician do a doctorate?

How do you differentiate between your practice and your research - in your own lives, in your own professional undertakings?

How do you see this relationship between practice and research then in an RHD program, authentically drawing from a professional perspective as above?

Comment on the notion of 'practice-led' and how this applies to your RHD. What is practice-led research, or what could it be?

Comments on the success or otherwise of the DMA programme design. Any comparisons to other RHD experiences and/or peer interactions you've had?

How do the relationships work over time? Do you have any concerns or practical suggestions re. 'managing your supervisor'. Coursework? Peer group potential? Other insights?

A faculty-wide RHD colloquium is provided; web resources aim to provide asynchronous communication and archival of material. What is best 'fit for purpose' re. the various stages of the RHD development process?

How does this relate to the prior practice-led discussion? How might this best evolve overall, form confirmation to completion?

The Dublin Descriptors for Third Cycle Awards in Music are proved as aspirational graduate attributes (Polifonia, 2007, p. 20). Do these reflect your experiences and understanding of your doctoral work? 